\title{
RANKING AMONG THE BEST IN ITS CATEGORY
}

Just in time for the company's 50th anniversary, a new version of DMG's LuxaPost composite root-post is now available which will make it even easier to work with confidence. The most important innovation is its significantly enhanced radiopacity; with a value of 375\% aluminium equivalent, LuxaPost ranks among the very best in its category.

Better visibility on X-rays gives the clinician additional confidence while working. Accuracy of fit can be better controlled and a more precisely fitted post reduces stress and potential fractures.

The glass-fibre reinforced LuxaPost is a tried and tested partner for LuxaCore Z-Dual, DMG's premium composite for core build-ups and root-post cementation. LuxaPost can be adhesively cemented with LuxaCore $\mathrm{Z}$, which is then used for the following core buildup, creating a stable system. Thanks to LuxaPost's optimised radiopacity, it is now even easier to be certain.

For comprehensive, coordinated post-endodontic treatment, DMG now offer a complete system. In addition to LuxaPost and LuxaCore Z-Dual, this includes LuxaBond-Total Etch, a dual curing adhesive system specially designed for use in the root canal.

For further information contact your local dental dealer or DMG Dental Products (UK) Ltd on 01656789401 or visit www.dmg-dental.com.

\section{OUTSTANDING ENDODONTIC TREATMENTS FOR YOUR PATIENTS}

EndoCare aims to become an invaluable member of your team, working closely with you to provide outstanding endodontic treatments for your patients.

When your patients visit EndoCare they will be greeted by a warm and friendly member of the team and will be guided and supported through every step of the way. EndoCare will also be sure to communicate with you promptly at each stage of treatment, to ensure that you are never left out of the loop. They will even recommend the type of restoration best suited to the case, appropriate timing, and any follow-up the patient may require either with EndoCare, or with you.

If you need to refer to an endodontist, trust EndoCare. Their team of experienced endodontists are all experts in their field, and are equipped with the very latest dental technology to ensure patients receive the very best care possible. If you'd like to find out more about how EndoCare works, or if you have a question for a member of the team, contact EndoCare today.

Call EndoCare on 02072240999 or visit www.endocare.co.uk.

\section{FULFILLING YOUR INFECTION CONTROL AND CONSUMABLE NEEDS}

Already renowned for providing some of the most effective decontamination equipment in the industry, Eschmann is now totally unique as the only manufacturer to supply a complete solution for all your infection control needs.

The new LittleSister autoclave represents the latest development in decontamination equipment, with new and improved safety features to ensure

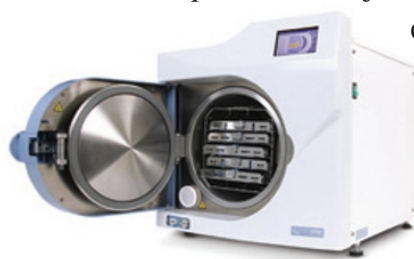

every single cycle is sterilised effectively. Created from decades of experience and understanding of the profession, the LittleSister boasts high quality and affordability.

Eschmann now provides all the consumables as well. The new essential range of cleaning and disinfection products includes a variety of highperformance sprays, wipes and liquids to decontaminate the entire dental environment. Continuing the theme of truly affordable solutions, the essential range is specifically designed to save you money every day.

For further information visit www. eschmann.co.uk or call 01903753322. 